\title{
Cartografia dos Atos Normativos do Ensino da Enfermagem antes da Lei No 775 de 1949
}

\author{
Cartography of Normative Acts of Nursing Education before Law Nº 775 of 1949
}

\author{
Maria Laiza de Souza ${ }^{1}$ \\ Roberlandia Evangelista Lopes ${ }^{2}$ \\ Silvia Maria Nóbrega-Therrien ${ }^{3}$
}

\section{Resumo}

Este artigo entende que a Lei n775, de 1949, impõe uma 'nova ordem' no momento em que institui legalmente a criação de outra categoria ocupacional na Enfermagem, no caso, a de auxiliar de Enfermagem, que passa, oficialmente, a trabalhar na área da saúde junto com a Enfermeira 'diplomada', sobretudo no contexto hospitalar, bem como a dividir com ela (Enfermeira) o mesmo espaço de formação e campo de atuação. Assim, tem-se por intuito realizar a cartografia dos atos normativos ${ }^{4}$ do ensino da Enfermagem, antes da promulgação da Lei $\mathrm{n}^{\circ} 775$, de 6 de agosto de 1949, destacando, nesse processo, os principais atores no campo da enfermagem presentes nessa legislação, uma vez que se tem o intuito de compreender que práticos e profissionais de enfermagem surgiram, legalmente, até 1949, bem como contextualizar as modalidades de formação e de práticas existentes. Metodologicamente, se priorizou a abordagem qualitativa e o estudo histórico, em especial, focou-se nos documentos escritos. Mas, para amparar essa decisão (uso de documentos), resolveu-se "enxergar" as fontes utilizadas neste estudo através da História Cultural.

\footnotetext{
${ }^{1}$ Graduada em Enfermagem pelo Centro Universitário UNITA (2018). Pós graduanda em Segurança do Trabalho. Envermeira da Prefeitura Municipal de Marco-CE. mlaizasouza15@gmail.com

${ }^{2}$ Doutora em Educação pela Universidade Estadual do Ceará, Brasil(2017). Professora do Curso de Enfermagem do Faculdades INTA, Brasil roberlandialopes@hotmail.com

3 Bolsista de Produtividade em Pesquisa 2 (CNPQ). Doutora em Sociologia em Educação pela Universidade de Salamanca, Espanha (2000) e Coordenadora do Laboratório de Educação e Saú da Universidade Estadual do Ceará , Brasil silth@gmail.com

${ }^{4}$ Entende-se por atos normativos o mesmo significado atribuído pelo Ministério da Saúde/Fundação Serviços de Saúde Pública (1974), ou seja, são Leis: normas ou conjunto de normas elaboradas pelo poder legislativo; Decretos: trata-se de um elemento regulamentador da Lei; Decretos-Lei: são um decreto que o chefe do Poder Executivo expede com força de lei para absorver as funções do legislativo eventualmente suspenso; Portarias: documento de ato administrativo de qualquer atividade pública que contém instruções a respeito da aplicação de leis e regulamentos, recomendações gerais, nomeações; Resoluções: instrumento legal normativo elaborado por órgãos colegiados (conselhos); Pareceres: são o estudo prévio de uma resolução; Estatuto: trata-se de alguns aspectos do regulamento; e, Regimentos: todas as normas específicas dos desdobramentos de uma norma geral da Instituição (BRASIL, 1974).
}

Recebido em 04 de setembro de 2018. Aprovado em 06 de agosto de 2020. 
Palavras-chave: Enfermeira. Formação. Legislação. Auxiliar de Enfermagem.

\begin{abstract}
This article understands that Law No. 775 of 1949 imposes a 'new order' when it legally establishes the creation of another occupational category in Nursing, in this case, the Nursing assistant, who officially starts working in the area with the 'graduate' nurse, especially in the hospital context, as well as to share with her (nurse) the same training space and field of action. Thus, it was intended to map the normative acts of nursing education, before the promulgation of Law No. 775 of August 6, 1949, highlighting, in this process, the main actors in the field of nursing present in each of these legislations. , since it is intended to understand that nursing practitioners and professionals legally emerged until 1949, as well as contextualizing the modalities of education and existing practices. Methodologically, the qualitative approach was prioritized and the historical study, in particular, focused on written documents. But to support this decision (use of documents) it was decided to "see" the sources used in this study through Cultural History.
\end{abstract}

Keywords: Nurse. Formation. Legislation. Nursing assistant.

\title{
Introdução
}

Esta pesquisa teve por intuito realizar a cartografia dos atos normativos ${ }^{5}$ do ensino da Enfermagem, antes da promulgação da Lei no 775, de 6 de agosto de 1949, destacando, nesse processo, os principais atores no campo da enfermagem presentes em cada uma dessas legislações, uma vez que se tem o intuito de compreender que práticos e profissionais de enfermagem surgiram, legalmente, até 1949, bem como contextualizar as modalidades de formação e de práticas existentes. Dito isto, interessa dizer que este artigo entende que a Lei n.775 de 1949 impõe uma 'nova ordem' no momento em que institui legalmente a criação de outra categoria ocupacional na Enfermagem, no caso, a de auxiliar de Enfermagem, que passa, oficialmente, a trabalhar na área da saúde junto com a Enfermeira 'diplomada', sobretudo no contexto hospitalar,

\footnotetext{
${ }^{5}$ Entende-se por atos normativos o mesmo significado atribuído pelo Ministério da Saúde/Fundação Serviços de Saúde Pública (1974), ou seja, são Leis: normas ou conjunto de normas elaboradas pelo poder legislativo; Decretos: trata-se de um elemento regulamentador da Lei; Decretos-Lei: são um decreto que o chefe do Poder Executivo expede com força de lei para absorver as funções do legislativo eventualmente suspenso; Portarias: documento de ato administrativo de qualquer atividade pública que contém instruções a respeito da aplicação de leis e regulamentos, recomendações gerais, nomeações; Resoluções: instrumento legal normativo elaborado por órgãos colegiados (conselhos); Pareceres: são o estudo prévio de uma resolução; Estatuto: trata-se de alguns aspectos do regulamento; e, Regimentos: todas as normas específicas dos desdobramentos de uma norma geral da Instituição (BRASIL, 1974).
} 
bem como a dividir com ela (Enfermeira) o mesmo espaço de formação e campo de atuação.

Por isso, frisa-se a necessidade de saber quem atuava na profissão antes desta promulgação e de fato entender como a Enfermeira se organizava legalmente neste cenário.

Além disso, o panorama político de saúde e educação em volta de cada tempo histórico onde a nova ordem se firma foi brevemente abordado neste escrito, assim como alguns feitos realizados por entidades/pessoas religiosas na área da saúde e da educação, pois esses campos são definidores de decisões tomadas e implementadas na forma da Lei no Brasil.

Com esse propósito, a análise e a discussão sobre a legislação no texto foi organizada por períodos históricos ocorridos no Brasil, obedecendo a uma sequência políticohistórica que se estruturou em épocas que vão passando pelo Brasil Império (18221889), República Velha (1890-1930) e Era Vargas (1930-1945).

\section{Metodologia}

Para atender a demanda de responder o problema da pesquisa mencionado anteriormente, coloca-se que o presente estudo histórico é de natureza qualitativa em sua abordagem. Tendo-se consciência de que existem inúmeras formas de compreender o passado, optou-se pela História Cultural (HC) como referencial teórico-metodológico para desenvolver esta investigação, especialmente focando o relacionamento da HC com as fontes e seu tratamento. Priorizou-se, metodologicamente, fontes documentais, especialmente foram utilizadas como fontes as falas do Estado (legislação da enfermagem).

"O documento não é mais, para a história, essa matéria inerte através da qual ela tenta reconstituir o que os homens fizeram ou disseram [...] ela procura definir, no próprio tecido documental, unidades, conjuntos, séries, relações" (FOUCAULT, 1995, p. 7).

Nessa lógica de entendimento, o artigo se ancora no trabalho de Luchese (2014) obedecendo, pelo menos, dois dos seis $^{6}$ critérios adotados pela autora em seu

\footnotetext{
${ }^{6}$ Os outros quatros critérios não adotados na tese são: as condições de produção do documento, a apropriação, as condições de circulação do documento e a preservação. O descarte dessas preocupações
} 
trabalho para análise documental, quais sejam: os procedimentos internos, que intentam perceber o que está escrito (o primeiro referente às ideias principais e secundárias) e o como está escrito (quais os procedimentos e o gênero da escrita, e quais os encadeamentos discursivos produzidos) e a materialidade do documento, permitindo analisar o tipo, as dimensões, o peso e as condições de funcionamento do suporte em que o documento se apresenta. Ademais, foram realizados aprofundamentos teóricos que, na medida do possível, auxiliassem as autoras deste artigo a dar conta das interpretações dos documentos encontrados e nela utilizados.

Considera-se importante pontuar que as pesquisas inseridas no campo da enfermagem não costumam referir o nome original dos entrevistados, com vista à resolução $\mathrm{n}^{\mathrm{o}} 466$ de 12, de dezembro de 2012, que resguarda os aspectos éticos da pesquisa ao lidar com seres humanos. Assim, o estudo foi encaminhado ao Comitê de Ética e Pesquisa da Universidade Estadual do Ceará (UECE), através da plataforma Brasil e, aprovado com a obtenção do seguinte parecer $\mathrm{n}^{\circ} 1.509 .938$.

\section{Resultados e Discussão}

Nos resultados deste artigo, apresentam-se os atos normativos do ensino da Enfermagem que foram sancionados nos seguintes tempos históricos: Brasil Império (1822-1889), República Velha (1890-1930) e Era Vargas (1930-1945), conforme se mencionou acima.

Dito isso, prossegue-se com a descrição interpretativa, apresentando o Quadro 01 a seguir que trata de demonstrar a legislação da enfermagem que foi promulgada em tempos do Brasil Império (1822-1889), assim como os respectivos atores nela envolvidos.

Quadro 1 - Os atos normativos do ensino da Enfermagem no tempo do Brasil Império (1822-1889). Fortaleza, Brasil, 2018.

\begin{tabular}{|l|l|l|}
\hline Ato normativo & Ano da sanção & Atores envolvidos \\
\hline Lei de sem numeração & 3 de outubro de 1832 & Parteira \\
\hline Decreto $\mathrm{n}^{\circ} 828$ & 29 de setembro de 1851 & Parteira \\
\hline
\end{tabular}

listadas por Luchese (2014) ocorreu por perceber que tais indagações pouco influenciariam na resposta da questão problema deste artigo. 


\begin{tabular}{|l|l|l|}
\hline Decreto $\mathrm{n}^{\circ} 1.387$ & 28 de abril de 1854 & Parteira \\
\hline Decreto $\mathrm{n}^{\mathbf{0}} 7.247$ & 19 de abril de 1879 & Parteira \\
\hline
\end{tabular}

Fonte: Elaborado pela autora.

O Quadro 01 evidencia que a parteira ${ }^{7}$ foi a primeira a ser formada com atividades inseridas no campo da Enfermagem, sendo referida em quatro atos normativos relacionados a essa profissão nos seguintes anos: 1832, 1851, 1854 e 1879. Ou seja, a parteira permanece por um período de 47 anos amparada legalmente em tempos de Império para exercer sua profissão. O Brasil, nessa época, tinha Dom Pedro II, como monarca do país. O modelo de monarquia parlamentarista adotado no Brasil conferia amplos poderes ao Imperador, o que resultava no total centralismo de suas decisões, entre elas as de cunho político, de saúde e de educação.

Logo, o país tinha como missão principal atender as necessidades da corte imperial instalada no Rio de Janeiro, desde 1808 e, dentre as necessidades mais urgentes, encontravam-se a saúde e a educação.

Sobre o quadro da saúde no Brasil, Escorel e Texeira (2008) afirmam que a partir de 1808 (Brasil colônia) foram criadas as primeiras instâncias de Saúde Pública, entre elas a Fisicatura-mor (extinta em 1828), que tratava de regulamentar e fiscalizar o comércio de alimentos e bebidas e as atividades relacionadas à arte de curar, com fins de combater a inúmeras epidemias ${ }^{8}$ da época.

Com a independência do Brasil (1815-1822), parte dessas tarefas de fiscalização foi transferida aos municípios, os quais, também, realizavam vacinação antivariólica em períodos de epidemias, faziam controle da entrada de escravos doentes nas cidades, a expulsão das áreas urbanas de acometidos por doenças contagiosas e a purificação do ambiente (Reforma Sanitária - 1928). Nesse período surgiram as primeiras Faculdades e agremiações médicas ${ }^{9}$.

\footnotetext{
${ }^{7}$ No estudo publicado por Maria Luiza Gonzalez Riesco (2009) o termo parteira é utilizado para designar tanto a profissional diplomada, como a parteira tradicional, também denominada leiga, curiosa, comadre ou aparadeira. Então, diplomada passa a ser a designação utilizada pelas parteiras formadas nas Escolas Médicas, em especial da Bahia e do Rio de Janeiro.

${ }^{8}$ No período de 1851 a 1860 , por exemplo, de acordo com as declarações do Médico da época, Dr. Pereira Rego, 40 epidemias atingiram a população da cidade do Rio de Janeiro e outras 18 no decênio de 1861 a 1870 (PERREIRA, 1872).

${ }^{9}$ Em 18 de fevereiro de 1808 foram criadas a Escola de Cirurgia da Bahia que, em 1832, passou a se chamar Faculdade de Medicina da Bahia.
} 
As inciativas de educação profissional no país, durante o Império (1822-1889), ora partiam de associações cíveis (religiosas e/ou filantrópicas), ora das esferas estatais das províncias legislativas do Império, de presidentes de províncias e de assembleias provinciais legislativas. Entre as Escolas profissionais nessa época, destacam-se as Escolas de Medicina, as Faculdades de Medicina da Bahia (criada em fevereiro de 1808) e a do Rio de Janeiro (criada em 5 novembro de 1808). Estas marcam os antecedentes específicos mediatos da profissionalização da área de Enfermagem, uma vez que o curso de parteiras (à época) era vinculado às Escolas Médicas ${ }^{10}$, que, por sua vez, impeliram a anexação de maternidades às Santas Casas de Misericórdia ${ }^{11}$.

Findando o Brasil Império (1822-1889), inicia-se a discussão do período histórico da República Velha (1890-1930). Nessa época, no Brasil, foram sancionados seis atos normativos relacionados à Enfermagem, dois a mais que no período anterior (Império), abarcando os 40 anos de existência desse período político, o que pode ser constatado no Quadro 02.

Quadro 2 - Os atos normativos da enfermagem na República Velha (1890-1930). Fortaleza, Brasil, 2018.

\begin{tabular}{|l|l|l|}
\hline Ato normativo & Ano da sanção & Atores envolvidos \\
\hline Decreto $\mathrm{n}^{\mathbf{0}} 791$ & 27 de setembro de 1890 & Enfermeiros e Enfermeiras \\
\hline Decreto $\mathrm{n}^{\mathbf{0}} 3.902$ & 12 de janeiro de 1901 & Parteira \\
\hline Decreto $\mathrm{n}^{\mathbf{0}} 15.230$ & 31 de dezembro de 1921 & Enfermeiros \\
\hline Decreto $\mathrm{n}^{\mathbf{0}} 15.799$ & 10 de novembro de 1922 & Enfermeiras diplomadas e \\
& & Enfermeiras Práticas \\
\hline Decreto $\mathrm{n}^{\mathbf{0}} 16.300$ & 31 de dezembro de 1923 & Enfermeiras diplomadas e \\
& & Visitadora de Higiene \\
\hline
\end{tabular}

Fonte: Elaborado pela autora.

Das cinco legislações promulgadas em formato de Decretos e dispostas no Quadro 02 acima, duas se referiram ainda à Parteira, pois essa profissão passou, desde o

\footnotetext{
${ }^{10}$ Situação que se mantém até 1949.

${ }^{11}$ Com relação à temática, afirma Graciette Borges da Silva (1986, p. 75) que no ano de "1543 foi à fundação da primeira Santa Casa de Misericórdia do Brasil - a de Santos, sendo em seguida fundadas as do Rio de Janeiro, Vitória, Olinda e Ilhéus. Em 1680 foi a de São Paulo [...] até o século XVIII as Santas Casas constituíram-se os únicos hospitais gerais existentes no Brasil”.
} 
ano de 1890, a conviver nos espaços geográficos brasileiros com Enfermeiras e Enfermeiros. Esta [Enfermeira], no entanto, é a primeira vez que aparece legalmente, no caso nos decretos de $\mathrm{n}^{\mathrm{o}} 791$ de $1890, \mathrm{n}^{\circ} 15.230$ de $1921, \mathrm{n}^{\mathrm{o}} 15.799$ de 1922 e no $^{\circ} 16.300$ de 1923. Constata-se, também, que nesse período novas denominações surgem para se referir a Parteira, mas, em ato legal, menciona-se a formação e o exercício desse profissional com essa denominação, como no caso do Decreto n ${ }^{\circ} 16.300$ de 1923. Contudo, Riesco e Tsunechiro (2002, p. 450), em seu escrito, assinalam que:

a denominação Parteira, como uma profissional distinta da Enfermeira foi utilizada até o ano de 1920 e a de Obstetriz apareceu pela primeira vez como o título conferido às formadas no Curso de Obstetrícia da Faculdade de Medicina e Cirurgia do Pará, entre 1922 e 1925.

Tal afirmação indica que a denominação para quem exercia essa profissão não era uniforme em todo território brasileiro, ou seja, os atos normativos, por vezes, a identificam como parteira, como foi feito nos atos legais do Brasil Imperial há pouco citados, como a Lei de 3 de outubro de 1832, o Decreto $n^{\circ} 828$ de 1851, o Decreto $\mathrm{n}^{\circ}$ 1.387 de 1854, o Decreto no 7.247 de 1879 e permanece no Decreto no 3.902 de 1901 (República Velha). A seguir (1925), a literatura, através de Riesco e Tsunechiro (2002), situa que o curso de Parteira da Faculdade de Medicina do Rio de Janeiro foi extinto e foram criados cursos de Enfermeiras de Maternidade, acrescentando, ainda, que em 1899 houve a criação do Curso de Obstetrícia em São Paulo e, em 1902, a instalação da Escola de Parteiras nesse mesmo Estado.

Retomando o Quadro 02, pode-se constatar quatro atos normativos citando Enfermeiros/Enfermeiras na República Velha (1890-1930) e que, após o Decreto no 791 de 1890, a outra legislação referente a essa denominação só é sancionada 31 anos depois por meio do Decreto de no 15.230 de 1921. A primeira referindo-se à criação da Escola de Enfermeiros e Enfermeiras do Hospital de Alienados (1890-1921), mais tarde designada de Escola de Enfermagem Alfredo Pinto (1921). Já o segundo ato normativo, ou seja, o Decreto de n ${ }^{\circ} 15.230$ de 1921 referindo-se à Escola de Aplicação do Serviço de Saúde do Exército $^{12}$. Outra instituição que aparece vinculada aos Decretos da República Velha (1890-1930) é a Escola de Enfermeiras do Departamento Nacional de

\footnotetext{
12 Esta Escola, desde sua fundação, recebeu as seguintes denominações ao longo dos anos: Escola de Aplicação Médico-Militar (1910); Escola de Aplicação do Serviço de Saúde do Exército (1921); e, Escola de Saúde do Exército (1933).
} 
Saúde Pública (1922), mais tarde denominada de Escola de Enfermagem Ana Neri (1923), através dos decretos $n^{\circ} 15.230$ de $1921, \mathrm{n}^{\circ} 15.799$ de 1922 e $\mathrm{n}^{\circ} 16.300$ de 1923.

Já as Visitadoras de Higiene ${ }^{13}$, que aparecem no Decreto no 6.300 de 1923 e que eram vinculadas à Escola de Enfermeiras do Departamento Nacional de Saúde Pública (1922), tinham sua formação voltada para a Saúde Pública, com caráter preventivo. Salienta-se que quando Ethel Parson ${ }^{14}$ chega ao Brasil, em 1921, e até a inauguração da Escola de Enfermeiras do Departamento Nacional de Saúde Pública, é lançado um curso de Visitadoras de Higiene sendo realizado em seis meses do referido ano. As visitadoras da época, segundo Medeiros (1924) e Fontenelle (1941), realizavam visitas domiciliares para fortalecer o vínculo com a família com a proposta, também, de promover a mudança dos padrões de comportamento a partir das ações de educação sanitária, vigilância sanitária e avaliação das relações familiares. Ainda por meio dessas ações, com base no conhecimento da higiene moderna, a agente (visitadora) promovia uma consciência sanitária individual e coletiva.

Por fim, sobre a denominação Enfermeira Diplomada, através dos atos normativos Decreto $n^{\circ} 15.799$ de 1922 e Decreto $n^{\circ} 16.300$ de 1923, tem-se a Escola de Enfermeiras do Departamento Nacional de Saúde Pública/Rio de Janeiro, criada especificamente pelo primeiro Decreto, ora citado, e que começou a funcionar em 1923, segundo Paixão (1979), com um grupo de 14 alunas. Essa instituição, no ano de 1926, passou a ser chamada Escola Ana Neri, sendo inspirada no modelo Nigthingaliano ${ }^{15}$. Por 10 anos (até a promulgação da Lei $n^{\circ} 775$, de 6 de agosto de 1949), foi a única do gênero no país, conforme assinala Forjaz (1955). Sobre a denominação das variações de profissionais na Enfermagem, ainda se observa no Quadro 02 a menção ao Decreto ${ }^{\circ}$ 15.799 de 1922 da terminologia Enfermeira Prática (primeira vez aparecendo em ato legal).

\footnotetext{
${ }^{13}$ Na dissertação de Lílian Fernandes Arial Ayres (2010, p. 161), sobre as enfermeiras da Cruz Vermelha brasileira do Departamento Nacional de Saúde Pública no início do século XX, têm-se informações mais completas sobre o Curso de Enfermeira Visitadora da Cruz Vermelha Brasileira (1914).

${ }^{14}$ Chefiava um grupo com outras 13 enfermeiras americanas para uma missão técnica da Fundação Rochefeller; agiu reorganizando a saúde pública e criando um curso rápido de visitadoras, entre outras ações no Departamento Nacional de Saúde Pública no Rio de Janeiro, em 1922.

${ }^{15}$ Apesar da existência secular da Enfermagem, a história da Enfermagem Moderna tem início a partir da segunda metade do século XIX com Florence Nightingale, na Inglaterra (SILVA, 1986; PIRES, 1989), o qual se baseava em criteriosa seleção das candidatas ao curso, na sistematização do ensino teórico e da prática correspondente e na total autonomia da escola em assuntos financeiros e pedagógicos. No entanto mantinha o caráter religioso e caritativo, servindo ao próximo como meio de aperfeiçoamento espiritual, principalmente aos pobres e necessitados (GERMANO, 1993).
} 
Feitas estas considerações sobre as várias denominações dos estratos da Enfermagem que aparecem em ato normativo na República Velha (1890-1930), inserese que, nesse período, o Brasil tinha um campo político marcado pela Proclamação da República em 1889, a Primeira Guerra Mundial (1914-1918) e a chamada Revolução de 1930 também acontecendo no país.

O campo da saúde no Brasil foi se constituindo, no decorrer da primeira República, entre a formação de cidades, a industrialização/imigração e a consequente aglomeração de pessoas em precárias condições de vida. Esses fatores facilitavam a proliferação de doenças infectocontagiosas, agravando, ainda mais, as condições de saúde da comunidade. As epidemias, que não eram novidade, impunham medidas urgentes por parte do Estado, como na análise que faz Rizzotto (2009, p. 427):

\begin{abstract}
isso contribuiu para que, nos primórdios da república, a saúde pública aparecesse como preocupação do governo, não só para reverter à péssima imagem que o Brasil estava produzindo no exterior, em decorrência de problemas dessa natureza, mas porque a "nova ordem republicana", balizada nos princípios liberais, embora politicamente excludente, defendia a universalização de certos serviços públicos como a saúde e a educação.
\end{abstract}

Na tentativa de resolver os problemas de saúde, agravados no início do período republicano, dentre outras medidas, o governo: criou o Conselho de Saúde Pública (1890); regulamentou o Laboratório de Bacteriologia (1892); criou o Instituto Sanitário Federal (1894); fundou a Diretoria Geral de Saúde Pública (1897); inaugurou o Instituto Soroterápico Municipal (1900); ordenou a notificação compulsória das doenças consideradas transmissíveis (1902); e, instituiu a obrigatoriedade da vacina contra a varíola (1904) (COSTA, 1986, p. 45/46). Acrescenta-se a esse quadro a criação do Departamento Nacional de Saúde Pública/Rio de Janeiro (1920) e a criação da Escola de Enfermagem do Departamento Nacional de Saúde Pública, antes mencionadas, devido ao acordo e a iniciativa de chamar a Fundação Rockefeller ${ }^{16}$ para contribuir com a modernização da saúde pública brasileira, em consonância com os ideais de cientificidade, racionalidade e higiene imperantes.

No início da República Velha (1890-1930) ocorre a promulgação da Constituição de 1891. De acordo com Cunha (1977), a Constituição determinou a

\footnotetext{
${ }^{16}$ Fundação criada em 1913, nos Estados Unidos da América, que define sua missão como sendo a de promover, no exterior, o estímulo à saúde pública, o ensino, a pesquisa e a filantropia.
} 
separação entre Estado e Igreja ${ }^{17}$, de modo que a religião passou da esfera pública para a esfera privada. Neste sentido, o Estado ficou proibido de financiar qualquer tipo de atividade religiosa, assim como nenhum ensino religioso poderia ser ministrado nas escolas públicas. Isso reflete diretamente na criação da primeira escola de Enfermagem do país, ou seja, o rompimento do Estado com a Igreja faz com que o primeiro ato normativo da Enfermagem seja promulgado na República Velha (1890-1930), no caso, o Decreto $\mathrm{n}^{\mathrm{o}} 791$, de 27 de setembro de 1890, que marca o início das escolas de formação da enfermagem, criando no Hospício Nacional de Alienados uma escola profissional de enfermeiros e enfermeiras, no Rio de Janeiro.

Outra Escola que trata de formar a Enfermeira é a Escola de Enfermeiras do Hospital Bom Samaritano, em São Paulo, em 1901, criada e dirigida por Enfermeiras Inglesas. Esta foi a primeira escola Ninghtingale organizada no país, entretanto, nenhum ato normativo faz menção da mesma à época. Também se destaca a fundação, em 1916, da Escola Cruz Vermelha Brasileira, intencionalmente criada pelo incentivo de um movimento internacional para melhorar as condições de assistência aos feridos na Primeira Guerra Mundial (1914-1918).

Após o fim desse período histórico e político (República Velha), recapitula-se que, até 1930, surgiram, com relação à enfermagem, as seguintes denominações: Parteira, Enfermeiros(as), Enfermeiros Militares, Visitadoras de Higiene e Enfermeiras Práticas, em ato legal.

Seguindo com os atos normativos, a Era Vargas (1930-1945) que, embora tenha durado somente 15 anos, se comparado aos períodos políticos discutidos anteriormente, promulga um número maior de Decretos sobre a enfermagem (sete), que podem ser observados no Quadro 03 ilustrado a seguir.

Quadro 3 - Os atos normativos da enfermagem na Era Vargas (1930-1945). Fortaleza, Brasil, 2018.

\begin{tabular}{|l|l|l|}
\hline Ato normativo & Ano da sanção & Atores Envolvidos \\
\hline Decreto $\mathrm{n}^{\mathbf{0}} 20.109$ & 15 de junho de 1931 & Enfermeiro diplomado ou \\
& & Enfermeira diplomada \\
\hline
\end{tabular}

\footnotetext{
${ }^{17}$ Institucionalmente, do princípio da separação da Igreja e Estado foi adotado, no contexto brasileiro, a partir do Decreto n ${ }^{\circ} 119$, de 7 de janeiro de 1890, mais especificamente em seu artigo 19, I: "é vedado à União, aos Estados, ao Distrito Federal e aos Municípios estabelecer cultos religiosos, ou igrejas, subvencioná-los, embarcar-lhes o funcionamento ou manter com eles ou suas representantes relações de dependência ou aliança, ressalvada na forma de lei, a colaboração de interesse público” (BRASIL, 1890).
} 


\begin{tabular}{|l|l|l|}
\hline Decreto $\mathrm{n}^{\mathbf{0}} 20.865$ & 28 de dezembro de 1931 & Enfermeiras Obstétricas \\
\hline Decreto $\mathrm{n}^{\mathbf{0}} 20.931$ & 11 de janeiro de 1932 & $\begin{array}{l}\text { Parteira e } \\
\text { Enfermeira Especializada }\end{array}$ \\
\hline Decreto $\mathrm{n}^{\mathbf{0}} 21.128$ & 7 de março de 1932 & Enfermagem Obstétrica \\
\hline Decreto $\mathrm{n}^{\mathbf{0}} 21.141$ & 10 de março de 1932 & Enfermeiros do Exército \\
\hline Decreto de $\mathrm{n}^{\mathbf{0}} 22.257$ & 26 de dezembro de 1932 & Irmãs de caridade \\
\hline Decreto $\mathrm{n}^{\mathbf{0}} 23.774$ & 22 de janeiro de 1934 & Enfermeiros práticos \\
\hline
\end{tabular}

Fonte: Elaborado pela autora.

Em relação às denominações para o pessoal de enfermagem, surgem dois novos profissionais até então não citados ou relacionados nas Leis/Decretos anteriores do tempo do Império (1822-1890) e da República Velha (1890-1930). Surgem, portanto, a Enfermeira obstétrica e especializada (denominação referente à Parteira) e as Irmãs de Caridade, sendo que os demais profissionais se mantêm iguais (Enfermeiros Militares, Enfermeiras práticas, Enfermeiros(as) e Parteiras); no entanto, a Visitadora de Higiene não é mais referida nesse tempo histórico em ato normativo. Sobre a variação de nomes relacionados à figura da parteira em ato legal, ou seja, às enfermeiras especializadas e obstétricas, Riesco e Tsunechiro (2002, p. 451) afirmam que:

assim, em 1925, o curso de parteiras da Faculdade de Medicina do Rio de Janeiro foi encerrado ${ }^{18}$. Em 1927, o currículo da Escola de Parteiras de São Paulo sofreu alterações e a disciplina Enfermagem Geral foi incluída no programa. Em 1931, a escola passou a denominar-se Escola de Obstetrícia e Enfermagem Especializada ${ }^{19}$, o currículo foi direcionado ao ensino da enfermagem e o curso passou a ter a duração de três anos; ao seu final, as alunas obtinham, além do título de Parteira, o de Enfermeira Especializada.

Já em 1931, a Escola de Parteiras de São Paulo muda o nome para Escola de Obstetrícia e Enfermagem Especializada, conferindo às alunas, ao final do curso, o título de Parteira e de Enfermeira obstétrica; porém, esta formação ainda estava vinculada às Faculdades de Medicina.

18 “Tal historiografia se baseia no Decreto $\mathrm{n}^{\mathrm{o}}$ 16.782-A, de 13/01/1925, também conhecido como Reforma Rocha Vaz, que recebeu essa denominação devido à participação do diretor da Faculdade de Medicina do Rio de Janeiro, Juvenil da Rocha Vaz, na sua efetiva elaboração. De acordo com esse Decreto, em seu art. 133, o curso de parteiras deveria ser suprimido e seria criado um curso para as enfermeiras de maternidades, em maternidades anexas às faculdades de medicina" (MEDEIROS, 2013, s/p.).

${ }^{19}$ Foram criadas, em 1931, as Escolas de Obstetrícia e Enfermagem Especializada (AMORIM, 2010). 
Considera-se relevante, ainda, citar que, em ato legal, é a primeira vez que surge a denominação Irmãs de Caridade como parte da Enfermagem, através do Decreto $\mathrm{n}^{\circ} 22.257$, de 26 de dezembro de 1932, lembrando que passam a atuar em Santas Casas do Brasil em 1543. Esse Decreto é uma resposta à sanção legal (Decreto $n^{\circ} 20.109$, de 28 de dezembro de 1931) que deu status social e científico à Escola Ana Neri, tornandoa padrão. Não só o Decreto n 20.109 de 1931 (relacionado às irmãs de caridade), mas o Decreto n 21.128, de 7 de março de 1932, o Decreto $\mathrm{n}^{\circ}$ 21.141, de 10 de março de 1932, e o Decreto $\mathrm{n}^{\mathrm{o}} 23.774$, de 22 de janeiro 1934, procuraram assegurar os mesmos direitos das Enfermeiras Ana Neri a, respectivamente, Enfermeiras obstétricas, Enfermeiros militares e Enfermeiras Práticas.

Referente à denominação Enfermeira diplomada, que aparece desde 1922 vinculada a Escola de Enfermeira do Departamento Nacional de Saúde Pública, e, mais a frente, a Escola Ana Neri (1926), mantém-se, em 15 de junho de 1931, através do Decreto $n^{\circ}$ 20.109. "A Escola de Enfermeiras Ana Neri, do Departamento Nacional de Saúde Pública, será considerada a escola oficial padrão" (BRASIL, 1974, p. 69).

Em meio a essas promulgações havia um contexto de rompimento político entre São Paulo e Minas Gerais nas eleições de 1930, pois Washington Luís decidiu apoiar o paulista Júlio Prestes em vez de apoiar o mineiro Antônio Carlos nas eleições presidenciais. Uma revolução vigorosa derrubou Washington Luís e entregou o poder político a Getúlio Vargas, como revelam Bruno e Farias (2012) sobre a finalização desse movimento.

A Revolução de 1930, na análise de Barreto (1942), congregou descontentes e descontentamentos de diversos tipos, além de ser um país governado por representantes das oligarquias estaduais, em particular pelos interesses agroexportadores dos estados do Sudeste-Sul do país. As críticas e as insatisfações eram também as mais variadas e ganharam contornos mais graves com a crise de $1929^{20}$. Em especial, complementa Hochman (2005, p. 128), isso levou:

\footnotetext{
a baixa incorporação política dos setores médios urbanos; as dificuldades de acesso ao poder de oligarquias não centrais; a corrupção política e eleitoral; a fragilidade do poder público federal; a ausência de integração nacional; a repressão policial aos movimentos reivindicatórios de trabalhadores; o clientelismo e o patrimonialismo; o atraso econômico; a carência de políticas sociais e as precárias condições de vida da população.
}

\footnotetext{
${ }^{20}$ Em 1929 houve a quebra da Bolsa de Valores de Nova York.
} 
No campo da saúde, Monteiro e Oguisso (2015) afirmam que estava envolvida uma estrutura fundamentada na reforma sanitária iniciada por Carlos Chagas na década anterior, com a criação do Departamento Nacional de Saúde pública (1922) voltado para a necessidade de combate às inúmeras epidemias que assolavam o Brasil. A criação do Ministério da Educação e Saúde acontece em 1930, e, em 1934, o Departamento Nacional de Saúde passa a ser chamado de Departamento Nacional de Saúde e Assistência Médico-Social, sendo que, em 1935 no Brasil, as práticas das campanhas sanitárias foram retomadas.

Outro fato relevante na saúde, que mais adiante tem um papel fundante na qualificação profissional de pessoal para essa área, consoante Luz (1978), foi a criação do Serviço Especial de Saúde Pública (SESP), em 1942. No que se refere ao campo educacional na Era Vargas (1930-1945), segundo Manfredi (2002), legitimou-se a separação entre trabalho manual e intelectual, erigindo uma arquitetura educacional que ressaltava a sintonia entre a divisão social do trabalho e a estrutura escolar, isto é, um ensino secundário destinados às elites condutoras, no caso da Enfermagem, a Enfermeira e outra aos ramos dos profissionais médios (para enfermagem - auxiliar de Enfermagem) do tipo técnico destinado às classes menos favorecidas.

Sobre o ensino de Enfermagem durante o Governo Vargas, constata-se que houve um grande investimento na área da educação, visto que este presidente percebia o ensino como um instrumento necessário para a formação de mão de obra qualificada. Tal estratégia teve repercussões no campo da educação em enfermagem, tanto que, entre 1930 e 1945, foram criadas 13 novas escolas de enfermagem, como revelam Baptista e Barreira (1997).

\section{Considerações finais}

A pesquisa que ora se apresenta teve o escopo de realizar a cartografia dos atos normativos do ensino da Enfermagem, antes da promulgação da Lei $n^{\circ} 775$, de 6 de agosto de 1949, destacando, nesse processo, os principais atores no campo da enfermagem presentes em cada uma dessas legislações

Mas para amparar essa decisão (uso de documentos) resolveu-se "enxergar" as fontes utilizadas neste estudo através da Historia Cultural. Por vezes, o caminho foi tortuoso, em especial pela falta de fontes documentais escritas preservadas, mas, 
encontrou-se não só ele (caminho tortuoso) também houve compensações, especialmente produzidas no crescimento da própria escrita.

Assim, a recuperação da trajetória, da institucionalização da enfermagem, suas tensões políticas e mutações históricas revelaram que antes da Lei 775 de 1949 houve a existência de diversas profissionais na categoria, reconhecidas legalmente, porém em sua maioria sem formação.

Logo, diante dos resultados obtidos, também se chega a um ponto de nova partida quando se sugere que estudos futuros voltem à temática e que estudos futuros possam ampliar o campo de investigação para quando acontece a inclusão de mais um membro que contribui para formar o que se conhece desde então (depois de 1949) como equipe de enfermagem.

Lacunas em estudos sobre a profissão e as condições ímpares de profissionalização da Enfermeira que enfrentou uma grande crise com a criação e implantação da nova ordem, são importantíssimos para se compreender como o passado conduziu o nosso presente, na tentativa de, se for o caso, redirecionar-se o futuro da Enfermeira. Logo, constata-se a necessidade de conhecer a história da profissão para entender aonde se chegou ou aonde se chegará; a (re)leitura de épocas e situações cunhadas em volta de cada passo dado, cada elemento agregado e retirado da profissão.

\section{REFERÊNCIAS}

AMORIM, Torcata. O resgate da formação e inserção da enfermeira obstétrica na assistência ao parto no Brasil. São Paulo: 2010. 290 f. Tese (Doutorado em Enfermagem) - Programa de Pós-Graduação na Escola de Enfermagem da Universidade de São Paulo, São Paulo, 2010.

AYRES, Lílian Fernandes Arial. As Enfermeiras visitadoras da cruz vermelha brasileira e do departamento nacional de saúde pública no início do século XX. Rio de Janeiro: 2010. 162 f. Dissertação (Mestrado em Enfermagem) - Programa de PósGraduação.

BAPTISTA, Suely Sousa de; BARREIRA, Ieda Alencar de. Condições de surgimento das escolas de enfermagem brasileiras (1890-1960). Revista Alternativa Enfermagem, Rio de Janeiro, v. 1, n. 2, p. 4-17, 1997.

BARRETO, João de Barros. A organização da saúde pública. Arquivos de Higiene, Rio de Janeiro, v. 12, n. 2, p. 169-215, 1942. 
BRASIL. Casa Civil. Subchefia para assuntos Jurídicos. Decreto $n^{\circ} 119-a$, de 7 de janeiro de 1890. Proíbe a intervenção da autoridade federal e dos Estados federados em matéria religiosa, consagra a plena liberdade de cultos, extingue o padroado e estabelece outras providencias. Diário Oficial da União, Rio de Janeiro, 7 jan.1890. Seção 1, p. 10. Disponível em: <http://www.planalto.gov.br/ccivil_03/decreto/1851-1899/d119a.htm.>. Acesso: 12 out. 2016.

BRASIL. Ministério da Educação e Saúde Pública. Enfermagem Legislação e assuntos correlatos. Rio de Janeiro: Guanabara, 1974.

BRUNO, Artur; FARIAS, Airton de. Fortaleza: uma breve história. Fortaleza: Edições Demócrito Rocha, 2012.

COSTA, Nilson Rosário do. Lutas urbanas e controle sanitário: origens das politicas de saúde no Brasil. Petrópolis: Vozes; 1986.

CUNHA, Luiz Antônio. Política educacional no Brasil: a profissionalização do ensino médio. Rio de Janeiro: Eldorado, 1977.

ESCOREL, Sarah; TEIXEIRA, Luiz Antonio. História das políticas de saúde no Brasil de 1822 a 1963: do império ao desenvolvimentismo populista. In: GIOVANELLA, Ligia et al. (org.). Políticas e Sistema de Saúde no Brasil. Rio de Janeiro: FIOCRUZ; CEBES, 2008. p. 333-384.

FONTENELlE, J. P. A. Enfermagem de Saúde Pública: Sua Criação e Desenvolvimento no Rio de Janeiro. Rio de Janeiro: Canton \& Reile Graf, 1941.

FORJAZ, Marina Vergueiro de. Função da Auxiliar de enfermagem. Revista de Enfermagem, Brasília, n. 4, p. 61-66, 1954.

FOUCAULT, Michel. O sujeito e o poder. In: DREYFUS, Hubert L.; RABINOW, Paul. Michel Foucault: Uma trajetória filosófica: para além do estruturalismo e da hermenêutica. Rio de Janeiro: Forense Universitária, 1995. p. 231-249.

GERMANO, R. M. Educação e Ideologia da Enfermagem no Brasil. São Paulo, Cortez Editora, $3^{\text {a }}$ ed., 1993.

HOCHMAN, Gilberto. Reformas, instituições e políticas de saúde no Brasil (19301945). Educar, Curitiba, n. 25, p. 127-141, 2005.

LUCHESE, Terciane Ângela. Modos de fazer história da educação: pensando a operação historiográfica em temas regionais. História da Educação, Porto Alegre,v. 18, n. 43, p. 145-161, maio/ago. 2014.

LUZ MADEL, Terezinha. Saúde e Instituições Médicas no Brasil. Saúde e Medicina no Brasil. In: GUIMARÃES, Reinaldo (Org.). Contribuição para um Debate. Rio de Janeiro: Graal, 1978. 
MANFREDI, Silvia Maria. História da Educação Profissional no Brasil. São Paulo: Cortez, 2002.

MEDEIROS, Aline Silva. A dinâmica hospitalar da Maternidade Dr. João Moreira, em Fortaleza, nas primeiras décadas do século XX. História, Ciencias, Saúde-Manguinhos, Rio de Janeiro, v. 20, n. 2, p. 653-673, abr./jun. 2013.

MEDEIROS, Amauri de. Cruzada Sanitária: Discursos. Recife: [s.n], 1924.

MONTEIRO, Bernardo Assis; OGUISSO, Taka. Visão histórica da Lei $n^{\circ} 755 / 49$ e seu impacto no Ensino de Enfermagem no Brasil. In: OGUISSO, Taka; FREITAS, Genival Fernandes. História da Enfermagem: Instituições \& Práticas de Ensino e Assistência. Rio de Janeiro: Águia Dourada, 2015. p. 31-47.

PAIXÃO, Waleska. História da Enfermagem. 5. ed. Rio de Janeiro: Júlio C. Reis, 1979.

PIRES, Denise. Hegemonia Médica na Saúde e a Enfermagem - Brasil: 1500 a 1930. Brasil. São Paulo, Cortez Editora, 1989.

RIESCO, Maria Luiza Gonzalez. Gerenciando conflitos na enfermagem obstétrica e neonatal interface entre as profissões de obstetriz e de enfermeira na assistência ao parto e nascimento: implicações para o ensino e o exercício profissional. In:

CONGRESSO BRASILEIRO DE ENFERMAGEM OBSTÉTRICA E NEONATAL. 7,2009, Teresina. Anais eletrônicos... Teresina: Faculdade nacional de medicina,2013. Não paginado. Disponível em:

<http://abenfopi.com.br/vicobeon/MREDONDAS/mlgr.pdf>. Acesso em: 11 maio 2017.

RIESCO, Maria Luiza Gonzalez; TSUNECHIRO, Maria Alice. Formação profissional de Obstetrizes e enfermeiras obstétricas: Velhos problemas ou novas possibilidades? Revista Estudos Feministas, Santa Catarina, v. 10, n. 2, p. 449-59,2002.

RIZZOTTO, Maria Lucia Frizon. A origem da enfermagem profissional no Brasil: determinantes históricos e conjunturais. Revista Brasileira de Enfermagem, Campinas, v. 59, n. esp., p. 423-7, 2009.

SILVA, G. B.(1986). A enfermagem profissional: uma análise crítica. São Paulo: Cortez. 